\title{
The Effects of a High-fat or High-sucrose Diet on Serum Lipid Profiles, Hepatic Acyl-CoA Synthetase, Carnitine Palmitoyltransferase-I, and the Acetyl-CoA Carboxylase mRNA Levels in Rats
}

\author{
Mi-Hyun Ryu and Youn-Soo Cha*, \\ Department of Food Science and Human Nutrition, Chonbuk National University, Chonju 561-756, Korea \\ Institute for Molecular Biology and Genetics, Chonbuk National University, Chonju 561-756, Korea
}

Received 14 January 2003, Accepted 7 February

The purpose of this study was to investigate the effects of altering relative intakes of fat and carbohydrates on serum lipid profiles, hepatic acyl-CoA synthetase (ACS), carnitine palmitoyltransferase-I (CPT-I), and the acetyl-CoA carboxlyase (ACC) mRNA level in Sprague-Dawley rats. For four weeks the rats were fed either an AIN-76 diet or one of its modified diets that were supplemented with $20 \%$ beef tallow (high-fat diet, HF) and $66.3 \%$ sucrose (highsucrose diet, HS). The HS group had significantly higher serum triglyceride and total cholesterol concentrations when compared with the other groups. Serum LDLcholesterol concentrations in the HS and HF groups were significantly higher when compared to the normal diet (ND) group. Serum HDL-cholesterol levels of the ND and HS groups were significantly higher than those of the HF group. The hepatic total lipid level of the HF group was significantly higher than those of other groups; triglyceride levels of the HS and HF groups were significantly higher than those of the ND group. Hepatic ACS mRNA levels of the HF group were significantly higher than those of the ND group. Hepatic CPT-I mRNA levels were higher in the HF group than other groups. Also, ACC mRNA levels in the liver increased in the HF group. In conclusion, changes in the composition of dietary fat and carbohydrates could affect the hepatic ACS, CPT-I, and ACC mRNA levels. These results facilitate our understanding of the coordinated regulation of the ACS, CPT-I, and ACC mRNA levels and will serve to enhance our understanding of the molecular mechanisms that underlie the regulation of fatty acid metabolism.

Keywords: Acetyl-CoA carboxylase, Acyl-CoA synthetase, Carnitine palmitoyltransferase-I, Dietary fat, Fatty acid metabolism

*To whom correspondence should be addressed.

Tel: 82-63-270-3822; Fax: 82-63-270-3854

E-mail: cha8@moak.chonbuk.ac.kr

\section{Introduction}

The formation of fatty acyl-CoA from fatty acid, ATP, and CoA that is catalyzed by acyl-CoA synthetase (ACS) is the first reaction in fatty acid metabolism. ACS plays a critical role in both the lipid synthesis of triacylglycerol, phospholipids, and cholesterol esters, as well as the $\beta$ oxidation of fatty acid. ACS, a member of the luciferase gene family (Suzuki et al., 1990), is located on the microsome and peroxisome in rat livers (Miyazawa et al., 1985). ACS mRNA is abundant in the liver, adipose tissue, heart, and skeletal muscle (Suzuki et al., 1990; Weiner et al., 1992).

Carnitine palmitoyltransferase-I (CPT-I), which is located on the outer mitochondrial membrane, is the rate-limiting enzyme for fatty acid oxidation. This enzyme catalyzes the formation of acyl-carnitine from acyl-CoA. This reaction is the first step of the transport of long-chain fatty acids from the cytosol into the mitochondrial matrix for fatty acid oxidation (McGarry and Foster, 1980; McGarry and Brown, 1997).

Acetyl-CoA carboxylase (ACC) catalyzes the carboxylation of acetyl-CoA to malonyl-CoA, the ratelimiting step in fatty acid synthesis. Malonyl-CoA that is synthesized by ACC is a critical material in the regulation of lipid metabolism, both the oxidation and synthesis of fatty acid. This provides acetyl groups during fatty acid synthesis, and inhibits the carnitine acetyltransferase-I (CPT-I) in the $\beta$ oxidation of long-chain fatty acids (McGarry et al., 1978; Bonnefont et al., 1999). Malonyl-CoA irregulation may induce insulin resistance and obesity (Ruderman et al., 1999; Loftus et al., 2000). ACC1 is the dominant isoform in the liver and adipose tissue. It is regulated long-term at the transcriptional and translational levels (Majerus and Kilburn, 1969; Bai et al., 1986), and short-term by the phosphorylation/dephosphorylation of serine residues and allosteric transformation (Thampy and Wakil 1988a, 1988b; Kim et al., 1989; Mabrouk et al., 1990; Mohamed et al., 1993). 
Metabolic abnormality of fatty acyl-CoA between oxidation and biosynthesis is linked to obesity. In this disease, fatty acyl-CoA is esterified and leads to triglycerol accumulation in the adipose tissue, muscle, liver, and pancreas (Koyama et al., 1997), which is positively associated with insulin resistance and hyperlipidemia (Koyama et al., 1997; Nassir et al., 1998; Shimabukuro et al., 1998).

Previous studies have shown that the ACS, CPT-I, and ACC genes are subject to dietary regulation (Shimomura et al., 1996). The ACS1 mRNA levels in rat livers are increased by refeeding with high-carbohydrate and high-fat diets (Suzuki $e t$ al., 1990); the hepatic ACS5 mRNA was also increased by refeeding with a high-sucrose diet, and decreased by a high cholesterol diet. Also, refeeding with a normal chow and highsucrose diet increased the hepatic ACS1 and ACS4 protein expression (Lewin et al., 2001). On the other hand, a high-fat diet increased the hepatic CPT-I activity and mRNA expression (Thumelin et al., 1994; Sohn et al., 1999; Lee et al., 2001), but a high-carbohydrate diet showed just the opposite results. Also, starvation and diabetes decrease the ACC1 activity, and refeeding with a carbohydrate diet induces the synthesis and activity of ACC1.

Despite the crucial role of ACS, CPT-I, and ACC in the regulation of fatty acid and carbohydrate oxidation, very few studies have proven that the dietary pattern affects the regulation of the ACS, CPT-I, and ACC at the same time, based on the molecular mechanism. Therefore, the aim of this experiment was to distinguish the effects of the dietary type, high-sucrose diet, and high-fat diet on the transcription levels of hepatic ACS, CPT-I, and ACC.

\section{Materials and Methods}

Materials DL-methionine, fiber, choline bitartrate, and a total RNA isolation kit were purchased from the Sigma Chemical Co. (St. Louis, USA). The AIN-76 vitamin and mineral mix were purchased from Harlan Teklad (Madison, USA). Casein was purchased from Cottee (Gordon, Australia). The psoralen-biotin labeling kit, nylon membrane, and detection kit was purchased from
Ambion (Austin, USA). All of the other chemicals were the highest commercial grade.

Animal and diets Male Sprague-Dawley rats (4 w of age and weighing about $150 \mathrm{~g}$ ) were purchased from Daehan Biolink Inc. (Eumsung, Korea) and randomly divided into three dietary groups; normal diet (ND), high-sucrose diet (HS), and high-fat diet (HF) groups. All of the diets were the AIN-76 and its modified versions, as published in cited references (Table 1). Each rat was individually housed in a stainless steel cage in a temperature, humiditycontrolled $\left(23 \pm 1^{\circ} \mathrm{C}, 53 \pm 2 \%\right)$ room. The animals were maintained on a light cycle ( $12 \mathrm{~h} / 12 \mathrm{~h}$ light/dark) with free access to diet and water. Twelve hours before the rats were sacrificed, the diet was removed from the cages to minimize the effect of food. The animal protocol was approved by the Animal Care and Use Committee of Chonbuk National University.

Sampling The feed intake and weight gain of the rats were recorded throughout the 4-week study. Blood was collected by decapitation, centrifuged at $1,100 \times g$ for $15 \mathrm{~min}$. at $4^{\circ} \mathrm{C}$, and the serum stored at $-20^{\circ} \mathrm{C}$ until assayed. The livers were collected and frozen in liquid nitrogen, and stored at $-80^{\circ} \mathrm{C}$ until analyzed.

Analysis of lipids The total lipids in the serum and liver were assayed by the sulfo-phospho-vanillin method (Frings and Dunn, 1970) using a commercial kit (Kokusai Pharm. Co., Kobe, Japan). The triglycerides in the serum and liver were enzymatically measured with a commercial kit (Asan Pharm. Co., Seoul, Korea) and the total serum cholesterol with a kit (Asan Pharm. Co., Seoul, Korea), based on the cholesterol oxidase method (Allain et al., 1974). Serum HDL-cholesterol was measured with a commercial kit from Asan Pharm. Co. (Seoul, Korea). Serum LDL-cholesterol was calculated from serum triglyceride, total cholesterol, and HDLcholesterol levels using the Friedewald formula (Friedewald et al., 1972).

ACS, CPT-I, and ACC mRNA levels Hepatic total RNA was isolated with a commercial total RNA isolation kit (Sigma, St. Louis, USA) using the guanidine thiocyanate/silica-based system. Total RNA was quantified by measuring the absorption at $260 \mathrm{~nm}$. ACS, CPT-I, and ACC mRNA abundance was measured by a Northern

Table 1. Composition of experimental diets

\begin{tabular}{lccc}
\hline \multicolumn{1}{c}{ Ingredient } & Normal diet $^{1)}$ & ${\text { High-Sucrose } \text { diet }^{2)}}^{\text {High-Fat }^{2}}$ \\
\hline Casein & 20.0 & 20.0 & 20.0 \\
DL-Methionine & 0.3 & 0.3 & 0.3 \\
Cornstarch & 15.0 & 3.0 & - \\
Sucrose & 50.0 & 66.3 & 50.0 \\
Fiber & 5.0 & 5.0 & 5.0 \\
Corn oil & 5.0 & 0.7 & - \\
Beef tallow & - & - & 20.0 \\
AIN Mineral mix & 3.5 & 3.5 & 3.5 \\
AIN Vitamin mix & 1.0 & 1.0 & 1.0 \\
Choline bitartrate & 0.2 & 0.2 & 0.2 \\
\hline \multicolumn{1}{c}{ Total $(\%)$} & 100.0 & 100.0 & 100.0 \\
\hline
\end{tabular}

${ }^{1)}$ American Institute of Nutrition, 1977; ${ }^{2}$ Park and Chyun, 1993; ${ }^{3)}$ Rim-Kim, 2001. 
Table 2. Gained body weight, feed consumption, energy intake, and feed efficiency ratio of rats

\begin{tabular}{|c|c|c|c|}
\hline & Normal group $(n=6)$ & High-sucrose diet group $(n=6)$ & High-fat diet group $(n=6)$ \\
\hline Gained body weight (g) & $137.49 \pm 1.14$ & $131.87 \pm 9.49$ & $147.22 \pm 9.37$ \\
\hline Feed consumption $(\mathrm{g} / \mathrm{d})$ & $19.39 \pm 1.92^{\text {a) }}$ & $19.61 \pm 1.74^{\text {a) }}$ & $15.53 \pm 2.04^{b)}$ \\
\hline Energy intake (kcal/d) & $71.8 \pm 17.27$ & $71.52 \pm 6.34$ & $72.52 \pm 7.56$ \\
\hline Feed efficiency ratio & $26.09 \pm 2.32^{b)}$ & $23.15 \pm 1.30^{\mathrm{c})}$ & $29.38 \pm 2.72^{\text {a) }}$ \\
\hline
\end{tabular}

All values are means $\pm \mathrm{SD}$.

Values with different superscripts in the same rows are significantly different $(p<0.05)$. Feed efficiency ratio was calculated as (total weight gain/total dietary intake) 100 .

Table 3. Serum and hepatic lipid profiles in rats

\begin{tabular}{|c|c|c|c|}
\hline & Normal group $(n=6)$ & High-sucrose diet group $(n=6)$ & High-fat diet group $(n=6)$ \\
\hline \multicolumn{4}{|l|}{ Serum } \\
\hline $\mathrm{TL}(\mathrm{mg} / \mathrm{dl})$ & $370.58 \pm 38.15$ & $350.89 \pm 39.09$ & $312.89 \pm 32.57$ \\
\hline $\mathrm{TG}(\mathrm{mg} / \mathrm{dl})$ & $48.48 \pm 0.51^{\mathrm{b})}$ & $77.84 \pm 14.03^{\mathrm{a})}$ & $57.35 \pm 7.50^{\mathrm{b})}$ \\
\hline $\mathrm{TC}(\mathrm{mg} / \mathrm{dl})$ & $82.55 \pm 2.71^{\mathrm{b})}$ & $107.43 \pm 7.03^{\mathrm{a})}$ & $80.43 \pm 3.13^{\mathrm{b})}$ \\
\hline HDL-C (mg/dl) & $42.88 \pm 4.82^{\mathrm{a})}$ & $48.59 \pm 3.95^{\mathrm{a})}$ & $30.20 \pm 7.08^{\mathrm{b})}$ \\
\hline LDL-C (mg/dl) & $30.16 \pm 6.90^{\mathrm{b})}$ & $44.32 \pm 3.48^{\mathrm{a})}$ & $51.18 \pm 8.68^{\mathrm{a})}$ \\
\hline \multicolumn{4}{|l|}{ Liver } \\
\hline TL (mg/g Liver) & $29.69 \pm 0.98^{b)}$ & $27.36 \pm 3.19^{\mathrm{b})}$ & $35.34 \pm 2.44$ a) \\
\hline TG (mg/g Liver) & $23.28 \pm 1.08^{b)}$ & $27.51 \pm 1.93^{\text {a) }}$ & $25.95 \pm 0.27^{\text {a) }}$ \\
\hline
\end{tabular}

All values are means $\pm \mathrm{SD}$.

Values with different superscripts in the same rows are significantly different $(p<0.05)$.

TL, Total lipid; TG, Triglyceride; TC, Total cholesterol; HDL-C, HDL-Cholesterol; LDL-C, LDL-Cholesterol.

blot analysis (Mynatt et al., 1994). Total RNA was loaded on 1.2\% agarose-formaldehyde gels, electrophoresed, and transferred to a nylon membrane (Ambion, Austin, USA). The ACS, CPT-I, and ACC DNA fragments that were obtained from the ACS, CPT-I, and ACC cDNA were labeled with biotin using the nonisotopic Psoralenbiotin labeling kit (Ambion, Austin, USA). Then a cDNA probe hybridization was performed in $100 \mu \mathrm{g} / \mu \mathrm{l}$ salmon sperm DNA, 50\% formamide, $6 \times$ SSC solution, $0.5 \%$ SDS, $5 \times$ Denhardts' solution at $42^{\circ} \mathrm{C}$ for $20 \mathrm{~h}$. To detect the biotinylated cDNA probes on a positively-charged nylon membrane, the membrane was washed to remove the non-specifically bound probe and incubated in a blocking buffer, conjugation and CDP-star solution using a BrightStar ${ }^{\mathrm{TM}}$ kit (Ambion, Austin, USA). The blots were exposed to X-ray film (Fuji, Tokyo, Japan) for $50 \mathrm{~min}$ and the bands quantified by densitometry.

Statistical analysis All of the values are expressed as group means \pm SD. The significance of differences was determined by an analysis of the variance (ANOVA) using SAS version 8 (SAS Institute, Cary, USA). When $p<0.05$ was obtained, the differences between the groups were considered statistically significant by Duncans multiple range test.

\section{Results and Discussion}

The following were evaluated: The effects of a high-sucrose diet (HS) versus a high-fat diet (HF) on serum and hepatic lipid profiles and rat liver mRNA levels of ACS, the first enzyme for fatty acid metabolism; CPT-I, the rate-limiting enzyme for fatty acid oxidation; and the ACC, the ratelimiting enzyme in fatty acid synthesis.

Rats that were fed HF ate significantly less than the other groups, but there was no difference in energy intake among the three groups (Table 2). The feed efficiency ratio was significantly higher in the HF group than the other groups, which was apparently due to the higher energy density of the HF diet. Body weight was higher in the HF group when compared to the ND and HS groups, but not significantly. The animals that were fed HS had significantly higher serum triglyceride and total cholesterol concentrations than the other groups (Table 3). Serum HDL-cholesterol in the HF group was significantly lower than those of the ND and HS groups. Serum LDL-cholesterol concentrations were significantly higher in both the HS and HF groups than in the ND group. Atherogenic indices were $1.77 \pm 0.58,1.21 \pm 0.07$, and $0.95 \pm 0.29$ in the HF, HS, and ND groups, respectively, but the differences were not statistically significant. Hepatic total lipid was significantly higher in HF, and hepatic triglyceride was significantly higher in both HF and HS (Table 3). Several studies have demonstrated that increased carbohydrate and saturated fat may induce obesity in the absence of increased energy intake (Oscai et al., 1987; Barnard RJ et al., 1998). This study also demonstrated that feeding HS and HF will 
induce increases of the serum LDL-cholesterol and hepatic triglyceride contents without an excessive energy intake. Some studies have reported that feeding sucrose increases plasma triglyceride (Koh et al., 1985), VLDL and LDLcholesterols (Albrink and Ullrich, 1986), and decreases the HDL-cholesterol concentration. Furthermore, Fernandez et al. reported that guinea pigs that were fed sucrose $(52 \% \mathrm{w} / \mathrm{w})$ exhibited increased levels of the hepatic HDL-binding protein (Fernandez et al., 1995). However, our results showed that the serum HDL-cholesterol concentration was higher in the HS group and lower in the HF group, and that the serum triglyceride level was higher in the HS group. It is unclear which mechanism is involved in the association between dietary sucrose and HDL-cholesterol. Therefore, more studies are needed to examine how a high-sucrose diet regulates the serum HDL-cholesterol level. It has been known for several decades that both high-carbohydrate and high-fat diets induce hypertriglyceridemia (Ahrens et al., 1957), and that hypertriglyceridemia typically accompanies insulin resistance (DeFronzo and Ferrannini, 1991). It has been shown that in the livers of obese Zucker rats, the fatty acid oxidation is decreased, but that the esterification of fatty acids and secretion of triglycerides are increased (Wang et al., 1981; Fukuda et al., 1982). The increased plasma triglyceride level that is associated with dietary sucrose might be due to either the increased secretion of triglyceride from the liver (Barnard et al., 1993), or from the decreased triglyceride removal from the plasma (Mamo et al, 1991). The circulating triglyceride concentration is determined by delivery into the plasma and subsequent removal of triglyceride-rich lipoproteins by tissues. Plasma triglyceride is derived from the diet and hepatic synthesis, and released as a very-low density lipoprotein (VLDL). Both the elevated free fatty acid and insulin levels promote hepatic triglyceride synthesis. A highfat diet in rats increased the long-chain acyl-CoA content of red muscle and liver (Chen et al., 1992). Therefore, it is expected that the HS and HF diets would induce increases in the acyl-CoA pool, and lead to increased triglyceride storage, as seen in this study (Table 3).

In evaluating the lipid metabolism difference between the two dietary patterns, we measured the hepatic ACS, CPT-I, and ACC mRNA levels of rats that were fed HS and HF. Northern blotting was carried out using hepatic total RNA from the rats that were fed the ND, HS, and HF diets. The hepatic ACS mRNA levels increased in the HS and HF groups, but only those of the HF group were significantly higher than the ND group (Fig. 1). These data suggest that, in the liver, the increased acyl-CoA content by feeding HF would be the result of the increased expression of ACS mRNA, and would lead to an increase of triglyceride synthesis and/or $\beta$-oxidation. The ACS-catalyzed reaction is the first step in the anabolism of free fatty acids to triglycerides or phospholipids, and in the $\beta$-oxidation of fatty acids. Thus, the expression levels of ACS may modulate the metabolic flux of acyl-CoA in the liver and adipose tissue that
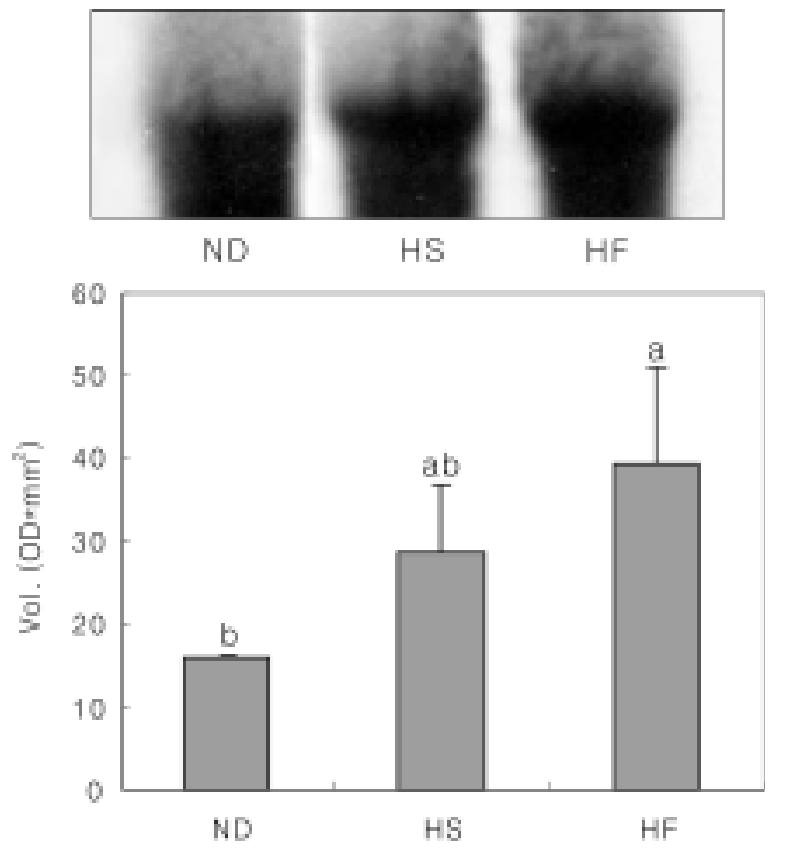

Fig. 1. Northern blot analysis showing changes in hepatic ACS mRNA. Total RNA $(25 \mu \mathrm{g})$ from rats fed the normal diet (ND) a high-sucrose diet (HS), and a high-fat diet (HF) was separater by $1.2 \%$ agarose gel electrophoresis and transferred to a nylor membrane. Hybridization and visualization were conducted a: described in Materials and Methods. The expression level ir each animal was quantified by densitometer. The values are thr means for six animals \pm SD. Values with different superscripts above the bar are significantly different $(p<0.05)$.

utilize fatty acids for the generation or storage of energy. ACS is associated with both microsomes and mitochondria in the liver, which activate fatty acid for esterification and oxidation, respectively. Also, Memon et al. reported that the hepatic microsomal ACS activity increased in obese mice, but the mitochondrial ACS activity increased in the control mice (Memon et al., 1999). Therefore, increased hepatic ACS activity would be expected during the states of increased lipogenesis and fat oxidation. The lipogenic enzyme gene expression in the rat liver is elevated by a fat-free, highcarbohydrate diet (Iritani 1992). Another study reported that hepatic ACS mRNA levels are increased in rats that were refed a fat-free, high-carbohydrate diet, which indicates that increased fatty acid and lipogenesis induces the ACS gene expression (Suzuki et al., 1990). In protein levels, refeeding a normal or high-carbohydrate diet also increased the ACS protein expression about 2 fold (Lewin et al., 2001). Moreover, it was reported that in Zucker ( $f a / f a)$ rats, the hepatic ACS activity and mRNA increased 1.2 and 1.8 fold, respectively. Also, hepatic acyl-CoA was utilized more for esterification to triacylglycerol (or triglyceride) than for $\beta$ oxidation when compared to the control rats (Azain et al., 1985; Shimomura et al., 1992).

The hepatic CPT-I mRNA levels in the rats that were fed 

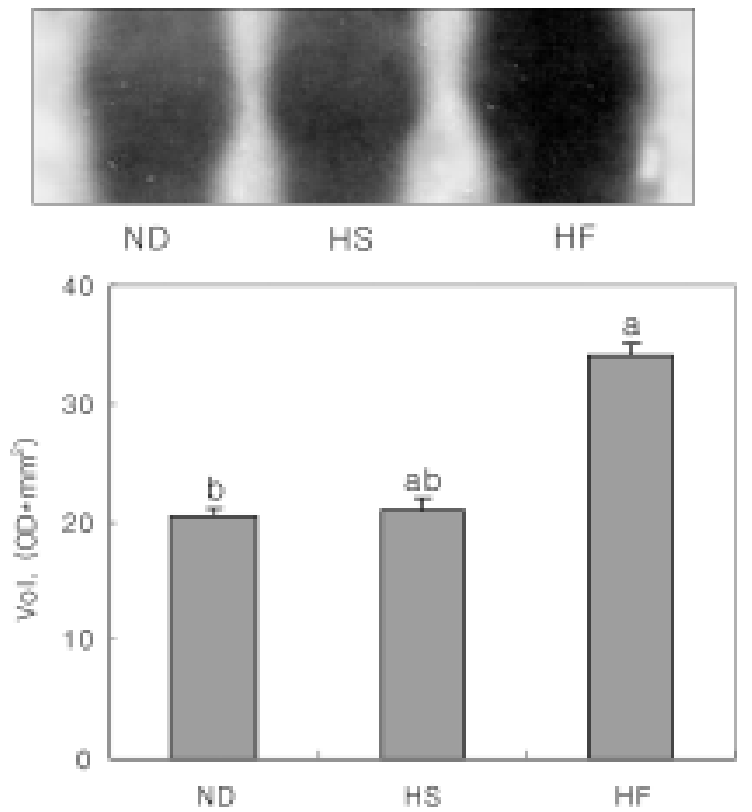

Fig. 2. Northern blot analysis showing changes in hepatic CPT-I mRNA. Total RNA $(25 \mu \mathrm{g})$ from rats fed the normal diet (ND), a high-sucrose diet (HS), and a high-fat diet (HF) was separated by $1.2 \%$ agarose gel electrophoresis and transferred to a nylon membrane. Hybridization and visualization were conducted as described in Materials and Methods. The expression level in each animal was quantified by densitometer. The values are the means for six animals \pm SD. Values with different superscripts above the bar are significantly different $(p<0.05)$.

HF was higher when compared to the rats that were fed ND and HS (Fig. 2). The capacity for hepatic fatty acid oxidation was enhanced by fasting, fat feeding, induced diabetes, or the treatment of rats with peroxisomal/mitochondrial proliferating agents. Also, the mRNA and activity levels of CPT-I were increased (McGarry and Brown, 1997; Bonnefont et al, 1999). In this special situation, the expression of CPT-I is required to obtain energy from fatty acids, the primary energy substrate. It is supposed that, in our study, an increase in the fatty acid substrate, by feeding HF, induces an increase in the expression of hepatic CPT-I mRNA in the HF groups. The activity, protein, and mRNA expression of hepatic CPT-I increased by feeding a high-fat diet, but decreased by feeding a highcarbohydrate diet (Thumelin et al., 1994; Lee et al., 2001). Also, the mRNA of CPT-I and the corresponding activity increased with starvation (Kolodziej et al., 1992). However, Saha et al. and Sidossis et al. suggested that the availability of carbohydrates rather than fat determines the rate of fat oxidation. Increased carbohydrate availability induces an increase of acetyl-CoA and malonyl-CoA in the muscle and liver. The increased malonyl-CoA content will inhibit CPT-I and decrease the fatty acid oxidation as a consequence of a high-carbohydrate diet (Saha et al., 1995; Sidossis et al., 1996). But, our results showed that hepatic CPT-I mRNA levels in the HS group were no different than those of the ND

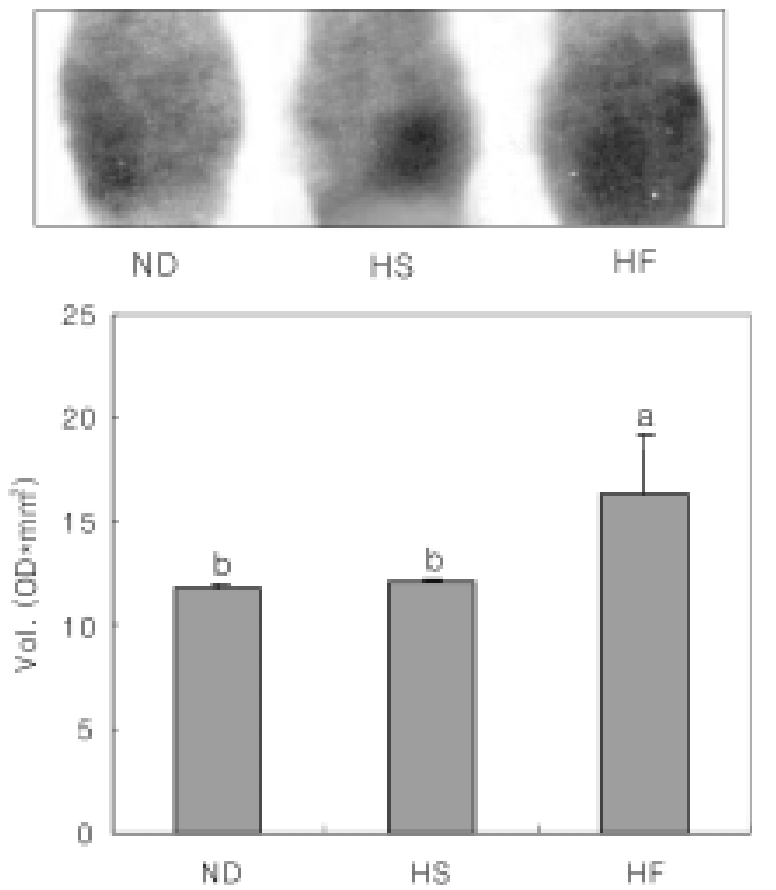

Fig. 3. Northern blot analysis showing changes in hepatic ACC mRNA. Total RNA $(25 \mu \mathrm{g})$ from rats fed the normal diet (ND), a high-sucrose diet (HS), and a high-fat diet (HF) was separated by $1.2 \%$ agarose gel electrophoresis and transferred to a nylon membrane. Hybridization and visualization were conducted as described in Materials and Methods. The expression level in each animal was quantified by densitometer. The values are the means for six animals \pm SD. Values with different superscripts above the bar are significantly different $(p<0.05)$.

group.

The hepatic ACC mRNA levels in the rats that were fed HF were higher than those in the rats that were fed ND and HS, which did not differ from each other (Fig. 3). ACC, the ratelimiting step in fatty acid synthesis, catalyzes the carboxylation of acetyl-CoA to malonyl-CoA. ACC is highly expressed in lipogenic tissues and is regulated at the transcriptional and translational levels or by the allosteric transformation of the enzyme (Mabrouk et al., 1990; Mohamed et al., 1993). Starvation and diabetes reduces both the mRNA and activity of ACC, and refeeding a carbohydrate-rich, fat-free diet induces the synthesis of ACC and increases its activity and mRNA (Pape et al., 1988). Also, ACC activities increased when weaned to a high-carbohydrate diet (Tsujikawa and Kimura, 1980), and the content of the hepatic ACC proteins diminished with fasting and increased refeeding of a high-carbohydrate diet (Bianchi et al., 1990). A paradoxical finding in this study was the increased expression of ACC mRNA in HF. Malonyl-CoA, synthesized by acetylCoA carboxylase (ACC), is a potent CPT-I inhibitor as well as the first committed intermediate in the pathway of fatty acid biosynthesis (Bonnefont et al, 1999). The increased mRNA expression is indicative of the increased malonyl-CoA and 
subsequent fatty acid synthesis. It is counter-intuitive that this would occur in the rats that were fed a high-fat diet and simultaneously with an increased CPT-1 expression. It is uncertain whether this represents a malfunction of the regulation of energy metabolism in the animals that were fed a high-fat diet, or if there is another explanation. However, dysfunction in the malonyl-CoA regulation is known to exist and contributes to insulin resistance (Ruderman et al., 1999) and obesity (Loftus et al., 2000).

In conclusion, altering the composition of dietary fat and sucrose affects the changes in the hepatic ACS, CPT-I, and ACC mRNA expression levels. Our study suggests that there is a coordinated regulation of ACS, CPT-I, and ACC at the transcriptional level by major energy nutrients.

\section{References}

Ahrens, E. H., Hirsch, J., Insull, W., Tsaltas, T. T., Blomstrand, R. and Peterson, M. L. (1957) The influence of dietary fats on serum lipids in man. Lancet 87, 943-953.

Albrink, M. J. and Ullrich, M. D. (1986) Interaction of dietary sucrose and fiber on serum lipids in healthy young men fed high-carbohydrate diets. Am. J. Clin. Nutr. 43, 419-428.

Allain, C. C., Poon, L. S., Chan, C. S., Richman, W. and Fu, P. C. (1974) Enzymatic determination of total serum cholesterol. Clin. Chem. 20, 470-475.

American Institute of Nutrition (1977) Report of the American Institute of Nutrition ad hoc committee on standards for nutritional studies. J. Nutr. 107, 1340-1348.

Azain, M. J., Fukuda, N., Chao, F. F., Yamamoto, M. and Ontko, J. A. (1985) Contribution of fatty acid and sterol synthesis to triglyceride and cholesterol secretion by the perfused rat liver in genetic hyperlipemia and obesity. J. Biol. Chem. 260, 174181.

Bai, D. H., Pape, M. E., Lopez-Casillas, F., Luo, X. C., Dixon, J. E. and Kim, K. H. (1986) Molecular cloning of cDNA for acetyl-coenzyme A carboxylase. J. Biol. Chem 261, 1239512399.

Barnard, R. J., Faria, D. J., Menges, J. E. and Martin, D. A. (1993) Effects of a high-fat, sucrose diet on serum insulin and related atherosclerotic risk factors in rats. Atherosclerosis $\mathbf{1 0 0}$, 229-236.

Barnard, R. J., Roberts, C. K., Varon, S. M. and Berger, J. J. (1998) Adipocyte and muscle changes in response to diet leading to obesity. Diab. Res. 33, 213-228.

Bianchi, A., Evans, J. L., Iverson, A. J., Nordlund A. C., Watts, T. D. and Witters, L. A. (1990) Identification of an isozymic form of acetyl-CoA carboxylase. J. Biol. Chem. 265, 1502-1509.

Bonnefont, J. P., Demaugre, F., Prip-Buus, C., Saudubray, J. M., Brivet, M., Abadi, and Thuiller, L. (1999) Carnitine palmitoyltransferase deficiencies. Mol. Genet. Metab. 68, 424440.

Chen, M. T., Kaufman, L. N., Spennetta, T. and Shrago, E. (1992) Effects of high-fat feeding to rats on the interrelationship of body weight, plasma insulin, and fatty acyl-coenzyme A esters in liver and skeletal muscle. Metabolism 41, 564-569.

DeFronzo, R. A. and Ferrannini, E. (1991) Insulin resistance: a multifaced syndrome responsible for NIDDM, obesity, hypertension, dyslipidemia, and atherosclerotic cardiovascular disease. Diabetes Care 14, 173-194.

Fernandez, M. L., Abdel-Fattah, G. and McNamara, D. J. (1995) Differential effects of simple vs. complex carbohydrates on VLDL secretion rates and HDL metabolism in the guinea pig. Biochim. Biophys. Acta 1256, 31-38.

Friedewald, W. T., Levy, R. I. and Fredrickson, D. S. (1972) Estimation of the concentration of low-density lipoprotein cholesterol in plasma, without the use of the preparative ultracentrifuge. Clin. Chem. 18, 499-502.

Frings, C. S. and Dunn, R. T. (1970) A colorimetric method for determination of total serum lipid based on the sulfophosphovanillin reaction. Am. J. Clin. Pathol. 53, 89-91.

Fukuda, N., Azain, M. J. and Ontko, J. A. (1982) Altered hepatic metabolism of free fatty acids underlying hypersecretion of very low density lipoproteins in the genetically obese Zucker rats. J. Biol. Chem. 257, 14066-14072.

Iritani, N. (1992) Nutritional and hormonal regulation of lipogenic enzyme gene expression in rat liver. Eur. J. Biochem. 205, 433442.

Kim, K. H., Lopez-Casillas, F., Bai, D. H., Luo, X. and Pape, M. E. (1989) Role of reversible phosphorylation of acetyl-CoA carboxylase in long-chain fatty acid synthesis. FASEB J. 3, 2250-2256.

Koh, E. T., Mueller, J., Osilesi, O., Knehans, A. and Reiser, S. (1985) Effect of fructose feeding on lipid parameters in obese and lean, diabetic and nondiabetic Zucker rats. J. Nutr. 115, 1274-1284.

Kolodziej, M. P., Crilly, P. J., Corstorphine, C. G. and Zammit, V. A. (1992) Development and characterization of a polyclonal antibody against rat liver mitochondrial overt carnitine palmitoyltransferase (CPT I). Distinction of CPT I from CPT II and of isoforms of CPT I in different tissues. Biochem. J. 282, 415-421.

Koyama, K., Chen, G., Lee, Y. and Unger, R. H. (1997) Tissue triglycerides, insulin resistance, and insulin production:implications for hyperinsulinemia of obesity. Am. J. Physiol. Endocrinol. Metab. 273, E708-E713.

Lee, J. S., Bruce, C. R., Spriet, L. L. and Hawley, J. A. (2001) Interaction of diet and training on endurance performance in rats. Exp. Physiol. 86, 499-508.

Lewin, T. M., Kim, J. H., Granger, D. A., Vance, J. E. and Coleman, R. A. (2001) Acyl-CoA synthetase isoform 1, 4, and 5 are present in different subcellular membranes in rat liver and can be inhibited independently. J. Biol. Chem. 276, 2467424679.

Loftus, T. M., Jaworsky, D. E., Frehywot, G. L., Townsend, C. A., Ronnett, G. V., Lane, M. D. and Kuhajda, F. P. (2000) Reduced food intake and body weight in mice treated with fatty acid synthase inhibitors. Science 288, 2379-2381.

Mabrouk, G. M., Helmy, I. M., Thampy, K. G. and Wakil, S. J. (1990) Acute hormonal control of acetyl-CoA carboxylase. $J$. Biol. Chem. 265, 6330-6338.

Majerus, P. W. and Kilburn, E. (1969) Acetyl coenzyme A carboxylase. The roles of synthesis and degradation in the regulation of enzyme levels in rat livers. J. Biol. Chem. 244, 6254-6262.

Mamo, J. C., Hirano, T., James, L., Szeto, L. and Steiner, G. (1991) Partial characterization of the fructose-induced defect in 
very-low-density lipoprotein triglyceride metabolism. Metabolism 40, 888-893.

McGarry, J. D. and Brown, N. F. (1997) The mitochondrial carnitine palmitoyltransferase system: from concept to molecular analysis. Eur. J. Biochem. 244, 1-14.

McGarry, J. D. and Foster, D. W. (1980) Regulation of hepatic fatty acid oxidation and ketone body production. Annu. Rev. Biochem. 49, 395-420.

McGarry, J. D., Takabayashi, Y. and Foster, D. W. (1978) The role of malonyl-CoA in the coordination of fatty acid synthesis and oxidation in isolated rat hepatocytes. J. Biol. Chem. 253, 82948300

Memon, R. A., Fuller, J., Moser, A. H., Smith, P. J., Grunfeld, C. and Feingold, K. R. (1999) Regulation of putative fatty acid transporters and acyl-CoA synthetase in liver and adipose tissue in ob/ob mice. Diabetes 48, 121-127.

Miyazawa, S., Hashimoto, T. and Yokota, S. (1985) Identity of long-chain acyl-CoA synthetase of microsomes, mitochondria and peroxisomes in rat liver. J. Biochem. 98, 723-733.

Mohamed, A. H., Huang, W. Y., Huang, W., Venkatachalam, K. V. and Wakil, S. J. (1993) Isolation and characterization of a novel acetyl-CoA carboxylase kinase from rat liver. J. Biol. Chem. 269, 6859-6865.

Mynatt, R. L., Park, E. A., Thorngate, P. E., Das, H. D. and Cook, G. A. (1994) Changes in carnitine palmitoyltransferase-I mRNA abundance produced by hyperthyroidism and hypothyroidism parallel changes in activity. Biochem. Biophys. Res. Commun. 201, 932-937.

Nassir, F., Bonen, D. K. and Davidson, N. O. (1998) Apolipoprotein(a) synthesis and secretion from hepatoma cells is coupled to triglyceride synthesis and secretion. J. Biol. Chem. 273, 17793-17800.

Oscai, L. B., Miller, W. C. and Arnall, D. A. (1987) Effects of dietary sugar and dietary fat on food intake and body fat content in rats. Growth 51, 64-73.

Pape, M. E., Lopez-Casillas, F. and Kim, K. H. (1988) Physiological regulation of acetyl-CoA carboxylase gene expression: effects of diet, diabetes, and lactation on acetylCoA carboxylase mRNA. Arch. Biochem. Biophys. 267, 104109.

Park, J. S. and Chyun, J. H. (1993) Effects of low fat diet and saturated fat supplementation on the immune status of BALB/c mouse. Korean J. Nutr. 26, 578-585.

Rim-Kim, J. C. and Kang, S. A. (2001) Effect of high-fat and high-carbohydrate diet on serum leptin and lipids-concentration in rats. Korean J. Nutr. 34, 123-131.

Rudeman, N. B., Saha, A. K., Vavvas, D. and Witters, L. A. (1999) Malonyl-CoA, fuel sensing, and insulin resistance. Am.
J. Physiol. 276, E1-E18.

Saha, A. K., Kurowski, T. G. and Ruderman, N. B. (1995) A malonyl-CoA fuel-sensing mechanism in muscle: effects of insulin, glucose, and denervation. Am. J. Physiol. 269, E283E289.

Shimabukuro, M., Zhou, Y. T., Levi, M. and Unger, R. H. (1998) Fatty acid-induced beta cell apoptosis: a link between obesity and diabetes. Proc. Natl. Acad. Sci. 95, 2498-2502.

Shimomura, I., Takahashi, M., Tokunaga, K., Keno, Y., Nakamura, T., Yamashita, S., Takemura, K., Yamamoto, T., Funahashi, T. and Matsuzawa, Y. (1996) Rapid enhancement of acyl-CoA synthetase, LPL and GLUT-4 mRNAs in adipose tissue of VMH rats Am. J. Physiol. 270, E995-E1002.

Sidossis, L. S., Stuart, C. A., Shulman, G. I., Lopaschukm, G. D. and Wolfe, R. R. (1996) Glucose plus insulin regulate fat oxidation by controlling the rate of fatty acid entry into the mitochondria. J. Clin. Invest. 98, 2244-2250.

Sohn, H. S., OH, S. H. and Cha, Y. S. (1999) Effects of exercise and/or high-fat diet on carnitine and carnitine palmitoyltransferase-I mRNA levels in rats. J. Korean Soc. Food. Sci. Nutr. 28, 670-676.

Suzuki, H., Kawarabayasi, Y., Kondo, J., Abe, T., Nishikawa, K., Kimura, S., Hashimoto, T. and Yamamoto, T. (1990) Structure and regulation of rat long-chain acyl-CoA synthetase. J. Biol. Chem. 265, 8681-8685.

Thampy, K. G. and Wakil, S. J. (1988a) Regulation of acetyl-CoA carboxylase. I. Purification and properties of two forms of acetyl-coenzyme A carboxylase from rat liver. J. Biol. Chem. 263, 6447-6453.

Thampy, K. G. and Wakil, S. J. (1988b) Regulation of acetyl-CoA carboxylase. II. Effect of fasting and refeeding on the activity, phosphate content, and aggregation state of the enzyme. J. Biol. Chem. 263, 6454-6458.

Thumelin, S., Esser, V., Charvy, D., Kolodziej, M., Zammit, V. A., McGarry, D., Girard, J. and Pegorier, J. P. (1994) Expression of liver carnitine palmitoyltransferase I and II genes during development in the rat. Biochem. J. 300, 583-587.

Tsujikawa, M. and Kimura, S. (1980) Changes in lipid synthesis in rat adipose tissue during development. J. Nutr. Sci. Vitaminol. 26, 367-374.

Wang, C. S., Fukuda, N. and Ontko, J. A. (1984) Studies on the mechanism of hypertriglyceridemia in the genetically obese Zucker rats. J. Lipid. Res. 25, 571-579.

Weiner, F. R., Smith, P. J., Wertheimer, S. and Rubin, C. S. (1992) Regulation of gene expression by insulin and tumor necrosis factor in 3T3-L1 cells. Modulation of the transcription of the genes encoding acyl-CoA synthetase and stearoyl-CoA desaturase. J. Biol. Chem. 266, 23525-23528. 